\title{
GAUDÍ Y EL MISTERIO DE LA ENCARNACIÓN (LAS INCÓGNITAS DE LA CRIPTA DE LA COLONIA GÜELL)
}

\section{(GAUDI AND THE MYSTERY OF THE ENCARNATION (THE MYSTERIES OF THE CRYPT OF THE COLONIA GÜELL))}

\author{
Albert Casals Balagué y José Luís González Moreno-Navarro, Arquitectos. \\ Profesores de construcción de la Escuela de Arquitectura de Barcelona de la Universidad Politécnica de Cataluña. \\ España
}

\section{RESUMEN}

La iglesia de la Colonia Güell fue el primer edificio relevante generado mediante la utilización -en un modelo tridimensional - de las lineas funiculares como sistema de determinación de formas estables. Un sistema ideado por Gaudi como mero instrumento de verificación de sus intuiciones estructurales y, sobre todo, de la viabilidad de sus intenciones plásticas. Ésta es la tesis de los autores del presente articulo, basado en la primera fase de los estudios que han de documentar la restauración de la cripta -única parte construida del edificio- y desvelar algunas de las incógnitas de este derrelicto arquitectónico que alienta todo tipo de fantasias y elucubraciones. Una de las incógnitas es la propia estabilidad de la cripta, bien comprobada, ya que sigue en pie. Si fue construida siguiendo parcialmente el modelo funicular estudiado por Gaudí para el edificio completo, y teniendo en cuenta que, naturalmente, era el conjunto el que estaba equilibrado, su estructura no está pensada para el parcial estado de cargas actual. También persiste la duda razonable de si el edificio hubiera sido estable una vez concluido siguiendo el proyecto funicular.

Las primeras conclusiones expuestas aqui no serán más que hipótesis hasta que los nuevos estudios en curso (que realizan los mismos autores por encargo también de la Diputación de Barcelona), con la modelización por elementos finitos, aporten nueva luz. Con todo, cualquier reflexión sobre la construcción de la Cripta adolecerá siempre de la escasez de material documental, una documentación perdida que hubiera permitido dilucidar mejor una de las claves esenciales del edificio: los criterios que rigieron el paso del hilo a la materia, es decir, su encarnación.

\section{SUMMARY}

The church of the Colonia Güell was the first significant building constructed with the use -in a three dimensional model - of funicular lines as a means for determining stable forms: a system conceived by Gaudi as a mere instrument of verification of his structural intuition and, above all, of the viability of his plastic intention. This is the thesis of the authors of this article, based on the first phase of the studies which are to document the restoration of the crypt - the only part of the building which was built- and reveal some of the mysteries of this architectural derelict which feed all sorts of fantasies and imaginations. One of these mysteries is the stability of the cript. If it was constructed partially following the funicular model studied by Gaudi for the complete building, and taking into consideration that, naturally, it was to be balanced whole, the constructed part must be unbalanced given that its current loads do not correspond to what the model foresaw. However, evidently the structure is stable as it has been standing for more than ninety years. $A$ reasonable doubt still persists with respect to the stability of the complete building once concluded following the funicular model.

The first conclusions here set down will be no more than hypotheses until new studies in course (being carried out by the authors for the Diputacion of Barcelona), with the modeling of the finite elements, shed new light. All together any reflections on the construction of the crypt will always suffer from a lack of documentary material. This lost documentation would have explained one of the essential keys of the building: the criteria which governed in the step from the string to its materialization, that is, its encarnation.

\section{La notoriedad de una obra inacabada}

La imagen de un edificio como la Cripta Güell, rodeado de un ralo bosquecillo de pinos, aparece a estudiosos y profanos acompañada de numerosas incógnitas y lagunas que actúan como poderosas espuelas de su imaginación cuando tratan de colmarlas.
Algunos se asombran del prodigio de un monumento que se puede recorrer en todos sus recovecos, incluso pasear por su cubierta, considerando como tal la del soportal que guarece la entrada a la Cripta.

Otros, hermenautas de ocasión, destilan múltiples interpretaciones sobre el simbolismo con que según ellos Gaudi revistió o debiera haber revestido todos y cada uno de los rincones de su obra. 


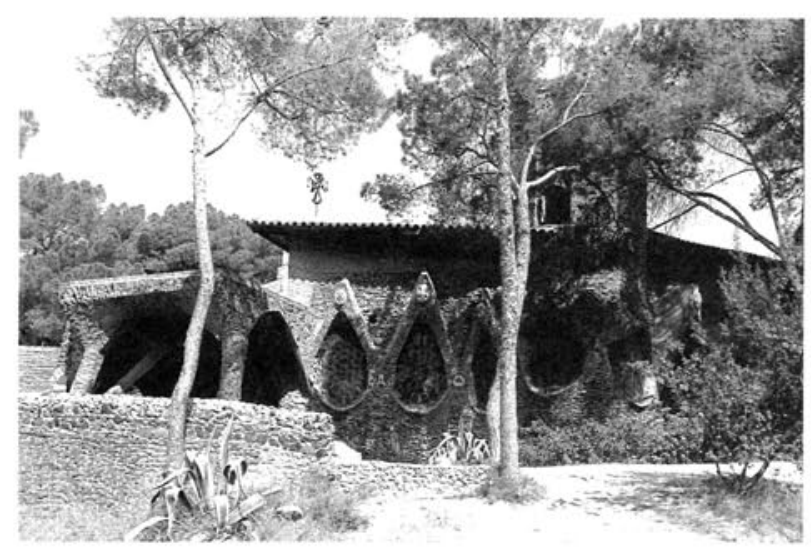

Fig. 1.- La Cripta desde el bosquecillo. (Foto Joan Francés, mayo 1990).

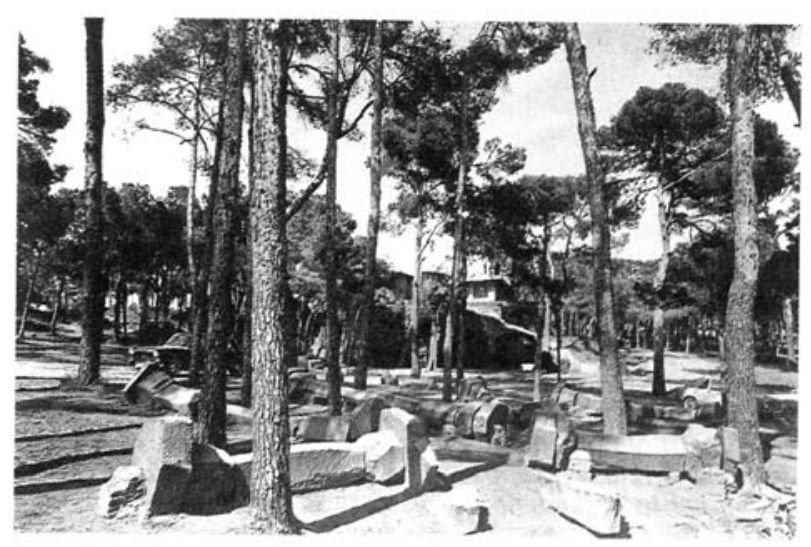

Fig. 2.-Testimonios de la inconclusión. (Foto Beascoa).

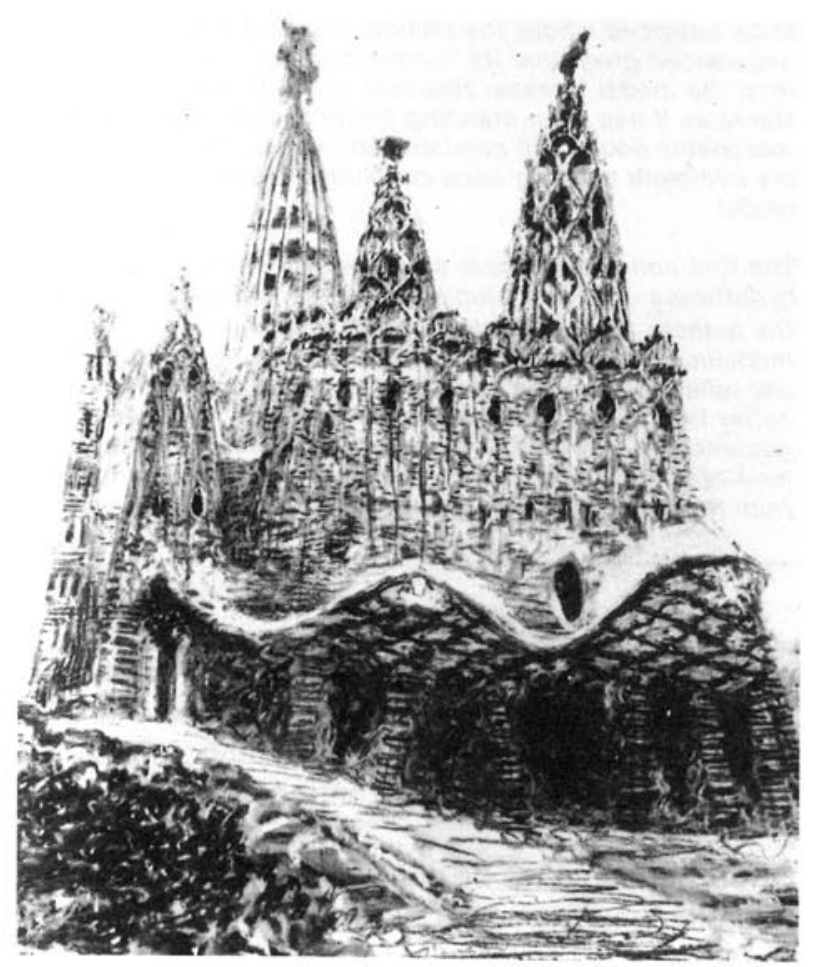

Fig. 3.-Una de las fotografias repintadas. (Foto parroquia Colònia Güell).
Los menos, más entendidos, admiran la franqueza de la expresión de los materiales de construcción, refiriéndose a la desnudez del ladrillo, sin percatarse de que la carencia de revestimiento se debe a la inconclusión de la obra.

No cabe duda que tantas lagunas e interrogantes son debidas, entre otras cosas, al insólito carácter de extraña obra interrumpida. En efecto, a finales de 1914 se detenian de manera definitiva los trabajos de construcción iniciados 6 años antes, a causa, se supone, de contrariedades financieras derivadas de la Gran Guerra. La imaginación queda asi más espoleada si cabe.

Los aficionados a los pasatiempos recreativos, se esfuerzan en reconstruir mentalmente la posición definitiva de los ciclópeos fustes, basas y capiteles de piedra basáltica dispersos por el exterior del monumento.

Los estudiosos intentan recrear, a partir de los extraños documentos existentes, el fantástico aspecto final sólo toscamente sugerido por unas seductoras y neblinosas fotografias repintadas. Sin duda, la inconclusión aporta a la Cripta una dimensión, no compartida por casi ninguna otra obra del maestro, que le hace partícipe de una condición de derrelicto de la Arquitectura, delante del cual, como delante de la mutilada Victoria de Samotracia, todo el mundo se esfuerza en ejercicios malabares de reconstrucción ideal, aunque no con ánimo arqueológico sino inventivo.

Pero ser un edificio inacabado no le ha impedido alcanzar el grado de notorio hito en el universo arquitectónico, incluso por encima del resto de creaciones del maestro.

Dos recientes referencias, de contextos y objetivos bien diferentes, pueden servir no sólo de comprobación, sino de constatación de que además la condición de hito se alcanza por duplicado y precisamente en el cumplimiento de los dos requerimientos generadores de la antinomia esencial de la Arquitectura.

Para Roger Scruton, que sitúa la referencia en lugar preeminente de su ensayo, la Cripta "es un edificio que trata de constituirse como algo diferente a la arquitectura, como una forma de desarrollo arbóreo más que como equilibrada ingeniería. (...) lo accidental ha pasado a ser esencial, y lo que pretende ser arquitectura ya no puede ser entendido como tal, sino sólo como obra escultórica, expresionista y complicada..." (1).

Por contra para Werner Blaser la Cripta se encuentra entre un selecto y paradigmático grupo de obras o propuestas ideales, en las que la organización constructiva que rige el descenso de cargas alcanza un papel predominante en la generación de laforma arquitectónica (2). 

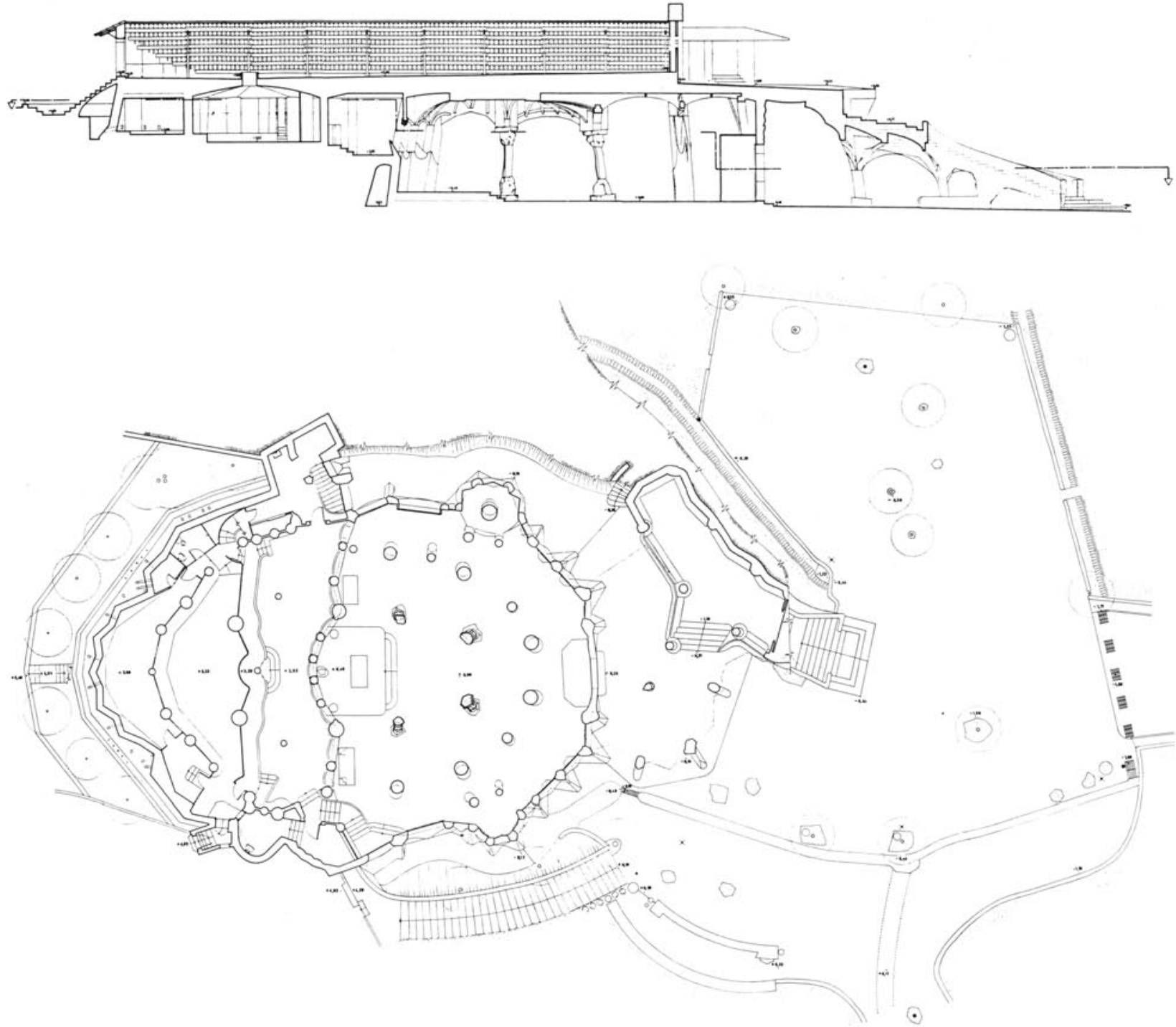

Fig. 4.- Sección longitudinal y planta general del estado actual de la Cripta y su entorno.

No parece lógico dudar que es el carácter poderosamente expresionista de la obra de Gaudi lo que le otorga la categoría de hito en el mundo de la estética arquitectónica, aunque la afirmación de Scruton pueda parecer extremada.

Sobre la segunda referencia, es casi obvio decir que su inclusión en ese destacado grupo de obras no es debido ni a su grandiosidad ni a su osadia en el límite de lo posible, virtudes que si definen la cúpula del Vaticano o el puente suizo de Ganter de $678 \mathrm{~m}$ de longitud, 100 de altura y 174 de luz. Lo que hace relevante esta modesta obra de Gaudi, cuya mayor dimensión sin apoyos es de $11 \mathrm{~m}$, y su altura 6 , son razones que se derivan de cuestiones metodológicas. Sin duda su categoria de hito en el mundo de la construcción arquitectónica se debe al insólito método utilizado por Gaudi como primera aproximación a su forma, método basado en las propiedades de los polígonos funiculares.

\section{La maqueta estéreo-funicular}

La utilización de las líneas funiculares como sistema de determinación de formas intrinsecamente estables ya era conocido desde épocas anteriores (3). Sin embargo ningún edificio relevante había sido generado siguiendo ese principio. Sin duda la Cripta es el primero. Pero además su carácter pionero se acrecienta por ser un conjunto de líneas funiculares trenzado en las tres dimensiones del espacio. Las limitaciones de los métodos gráficos o numéricos existentes en la época obligan a Gaudi a desarrollar su estéreo-funícula mediante un modelo real a escala.

Pero para Gaudi el modelo no pasa de ser un mero instrumento. Según sus propias manifestaciones “... pretender que las funículas den las formas de la Arquitectura es pueril, porque constituyen sólo un método de verificación o de comprobar la eștabilidad (...) antes de la estabilidad hay otras cosas a satisfacer, ca- 


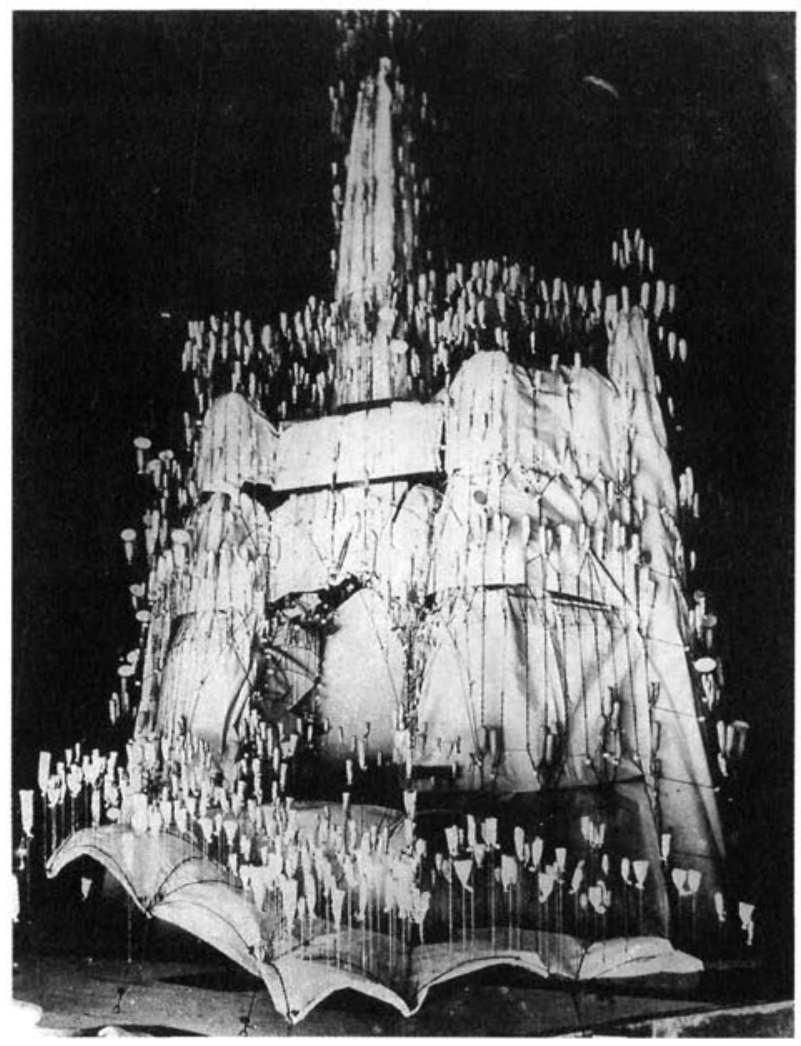

Fig. 5.-Visión invertida de la maqueta original. (Foto Cátedra Gaudi).

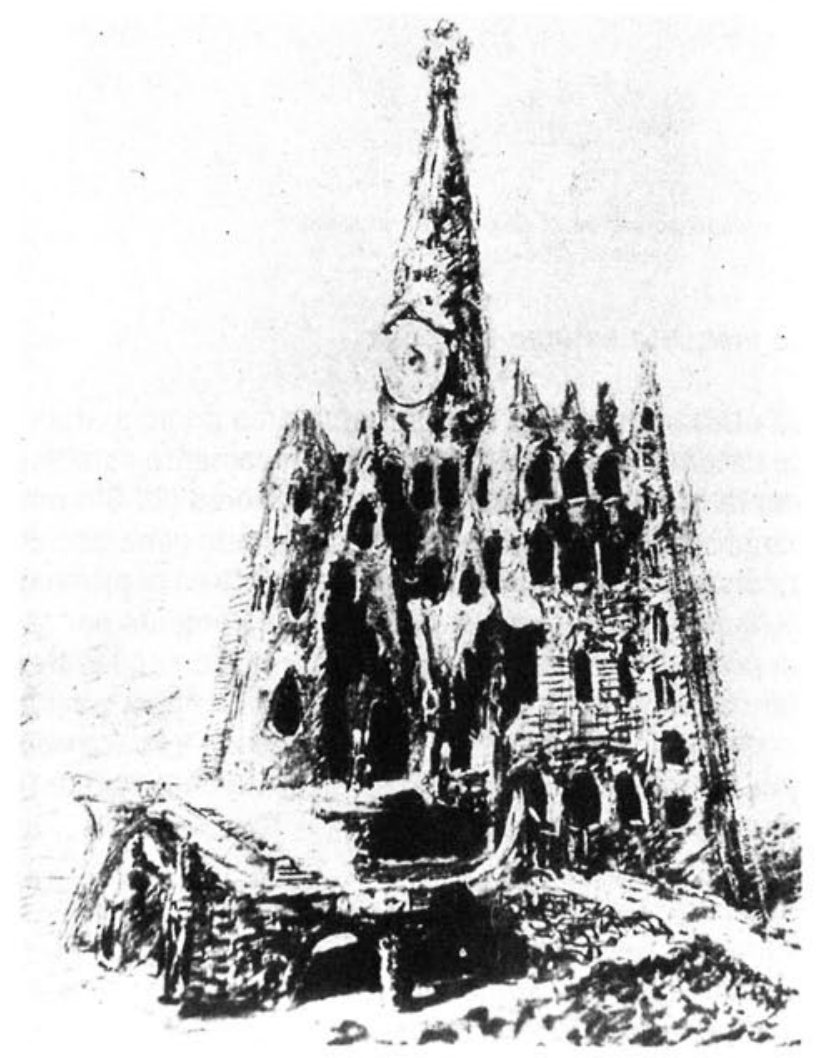

Fig. 6.-Croquis de la iglesia hecho a partir de la fotografia anterior. (Foto Cátedra Gaudi). pacidad, iluminación, relación ordenada de servicios, etc..." (4). Y por supuesto, aunque no lo mencione, una voluntad casi incontenible de expresión plástica.

Una simple contemplación de la Cripta sirve para convencer al más escéptico de que la voluntad de creación de formas en si mismas domina tanto sobre los juegos constructivo-mecánicos, como sobre las adecuaciones al uso litúrgico.

Pero son unas formas que, gracias al artilugio funicular, en su propia esencia está presente la optimización constructivo-mecánica. Gaudi crea formas de una desbordante expresividad plástica pero limitada, y también potenciada, por su profundo conocimiento de las leyes que rigen el comportamiento de la materia construida. Su actuación es muy diferente de la del frívolo formalista que ignora los limites y las posibilidades de la organización constructiva de los materiales proponiendo formas inconstruibles o infinanciables.

Naturalmente, un tal proceso creativo no puede estar exento de conflictos, de manera que los dramas de la antinomia básica de la Arquitectura también están presentes en la obra gaudiniana. Como puede comprobarse en bastantes rincones de la Cripta, la constante lucha entre plástica y construcción también se desequilibra en ocasiones en la obra del maestro.

Es notablemente amplia la bibliografía que se extiende sobre todo lo antedicho, desde las iniciales disquisiciones de Rubió a las inextricables reflexiones de Matsukura (5).

Sin embargo, hasta que la entusiasta iniciativa de un grupo de holandeses y alemanes admiradores de lo gaudiniano (6), no lleva a cabo la ingente tarea de reconstruir el modelo colgante, se carece de instrumentos realmente eficaces para aumentar el conocimiento sobre la generación de esta particular forma arquitectónica.

El modelo reconstruido y la publicación que relata la laboriosa y prolija experiencia de su elaboración (7), son una aportación de inusitado valor, basada en el rigor metodológico y no en la especulación retórica. El trabajo realizado por Jos Tomlow y su notable grupo de colaboradores es de mayor interés del que se puede deducir del extracto publicado recientemente en estas páginas (8).

La única actitud razonable por parte de los que aman la obra de Gaudi sólo puede concretarse en un hondo agradecimiento hacia aquellos que han tenido el coraje de elaborar lo que a nosotros, como paisanos del maestro, nos correspondia y no herrtos sabido o podido emprender. 
En consecuencia, no son admisibles criticas que no advierten que el único objetivo del trabajo de los holandeses es "sólo" reproducir físicamente el modelo de Gaudi (9).

\section{La encarnación del modelo}

El presente artículo se basa en la primera fase de los estudios en curso que han de documentar la necesaria puesta al día de la Cripta y pretende engrosar, aunque modestamente, la bibliografía citada (10).

Un nuevo levantamiento de planos ayudado de prospecciones de zonas ocultas, junto con una primera aproximación al comportamiento mecánico del conjunto y la observación del modelo real reproducido, han permitido llegar a conclusiones novedosas, que, como casi siempre y más en este caso, son provisionales de manera casi definitiva.

Cualquier reflexión sobre la constitución constructiva de la Cripta, ya elaborada o por elaborar, adolece de la cortedad de material documental que dilucide una de las claves esenciales del edificio: los criterios que rigieron el paso del hilo a la materia, es decir, su encarnación.

Los lamentables sucesos que provocó la rebelión militar de la década de los treinta hicieron desaparecer, según cuentan los cronistas, además del modelo funicular todavía conservado, una enorme cantidad de planos y croquis que Gaudi habia ido confeccionando durante el proceso de construcción. Sólo unas cuantas fotografias de la maqueta, que se salvaron de aqueIlo, permiten aventurar algunas ideas.

Pero el hecho de que el objetivo prioritario de Gaudí fuera lógicamente el cuerpo principal del edificio, la iglesia superior, no hace sino agravar el problema. Las fotografías se centran casi exclusivamente en la parte inferior de la maqueta, o parte superior del edificio. Los trazados de los elementos de la Cripta sólo aparecen subsidiariamente en algunas de las vistas que buscan sobre todo definir el espacio principal del edificio (11). Paradójicamente la parte construida carece de documentación, y la que existe sólo se refiere a la no nata.

Este hecho va a impedir que bastantes incógnitas de la estructura de la Cripta queden definitivamente despejadas. El modelo reconstruido tampoco coopera en su dilucidación ya que arranca con las mismas carencias iniciales.

La incógnita básica parece que quedará sin desvelar: el porqué de la concreción en obra de fábrica de mamposteria y ladrillo. El modelo funicular asegura unas directrices que impiden la aparición de esfuerzos de tracción, siempre que la línea de presiones no desborde el núcleo central, y en consecuencia facilita su directa concreción en obra de sillería aparejada estereotómicamente. Sin embargo, Gaudí recurre a fábricas coherentes que aportan cierta resistencia a tracción. Las constantes referencias a que la Cripta es un campo de experimentación para la Sagrada Familia (12) podrían hacer suponer más lógica la utilización de los procedimientos del picapedrero frente a los del albañil. No obstante, éste es el que tiene un protagonismo casi total en la Cripta. La razón quizá resida en la economía del promotor, o en la ubicación geográfica de la obra.

Pero un estudio más atento del edificio permite sospechar que la auténtica razón está en que permitió a Gaudi una encarnación mucho más libre que la que le hubiera exigido el adovelado. El paso del hilo al ladrillo y al mampuesto no es ni mucho menos un paso simple o directo, sino que es fruto de un proceso de creatividad plástica y constructiva inigualable. La distancia entre la escueta delgadez de los hilos y la extraordinaria riqueza y robustez de su materialización latericia o pétrea es prueba innegable de todo ello, tal como ayuda a comprender la comparación del modelo holandés con la realidad construida (13).

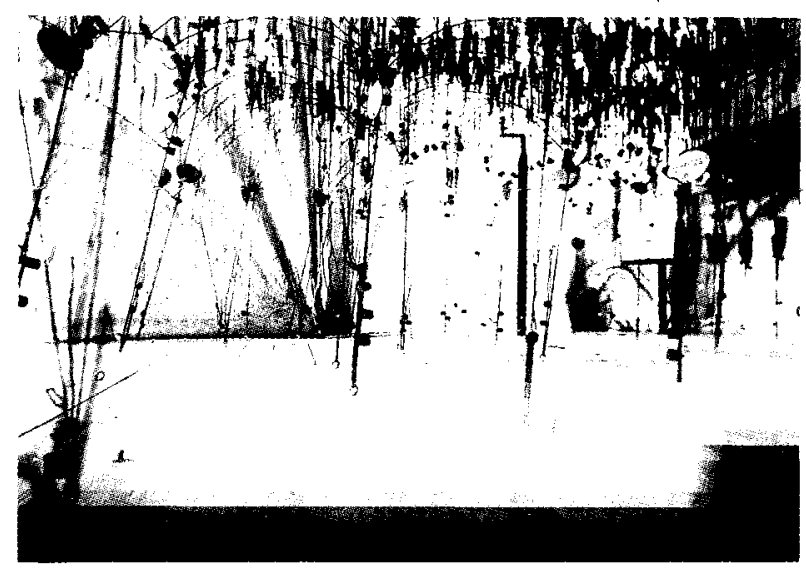

Fig. 7.-Única foto de la maqueta original en la que se observa di rectamente la parte correspondiente a la Cripta. (Foto Catedra Gaudi).

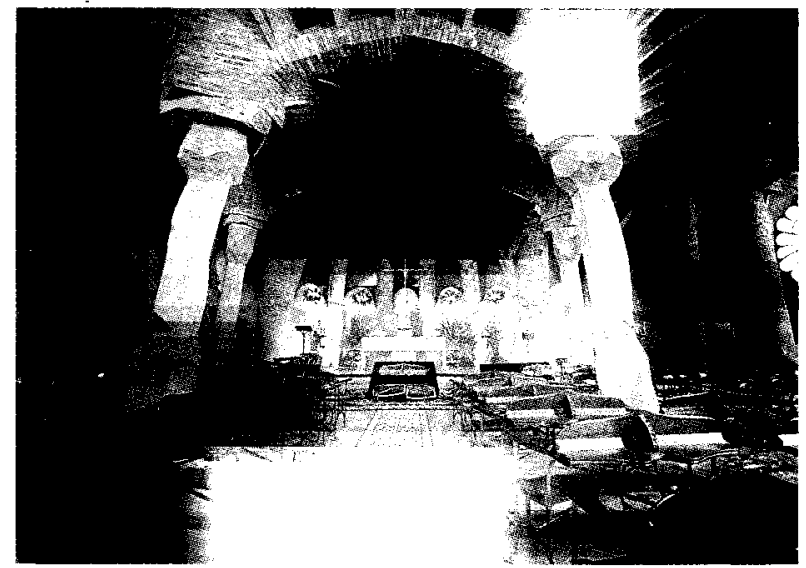

Fig. 8.-Interior de la Cripta. (Foto Arxiu Mas, 1968). 


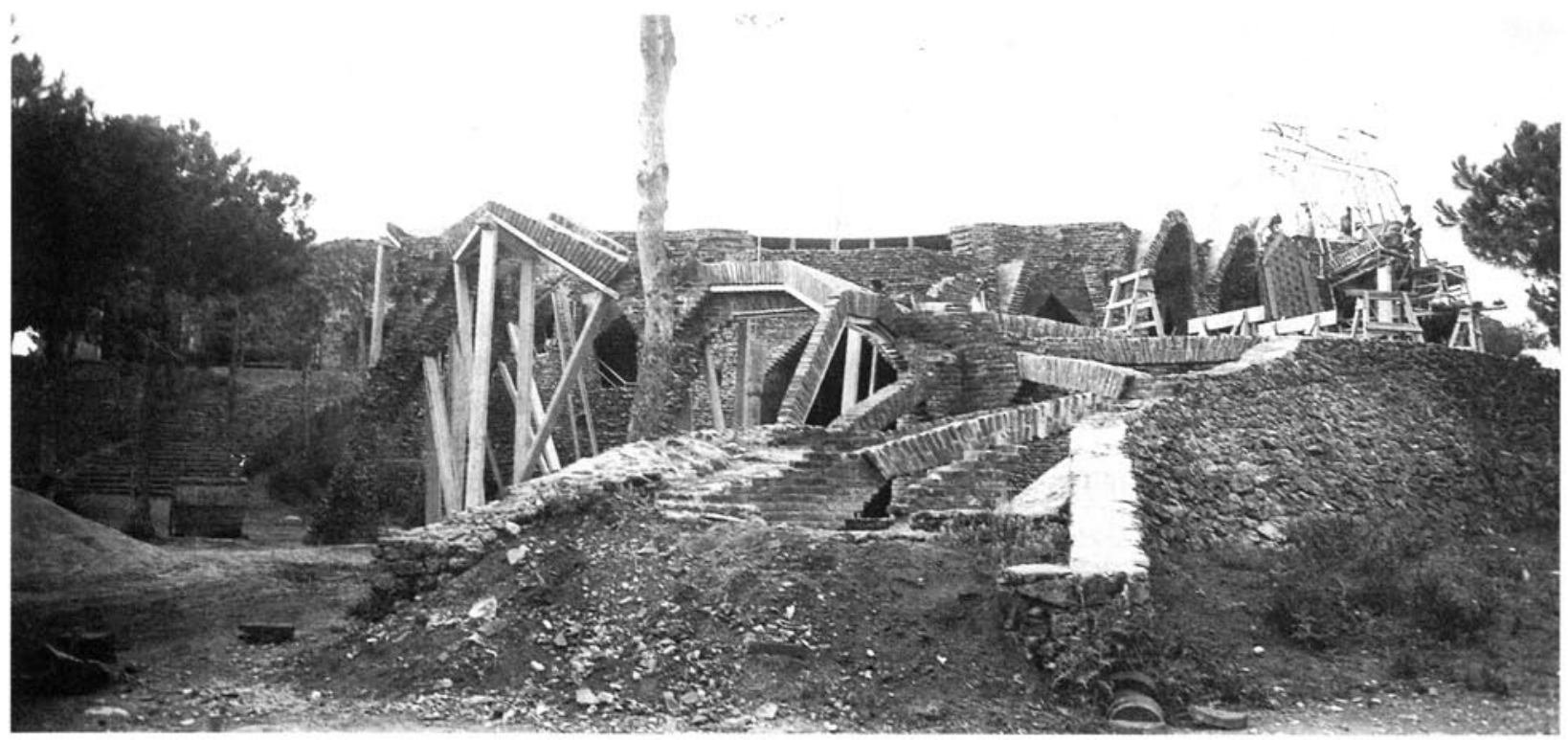

Fig. 9.-En los nervios del porche es donde se advierte con mayor claridad la diferencia entre la realidad construida y las lineas funiculares de la maqueta. (Foto Antonio Gallardo-Arxiu SPADB, hacia 1908).

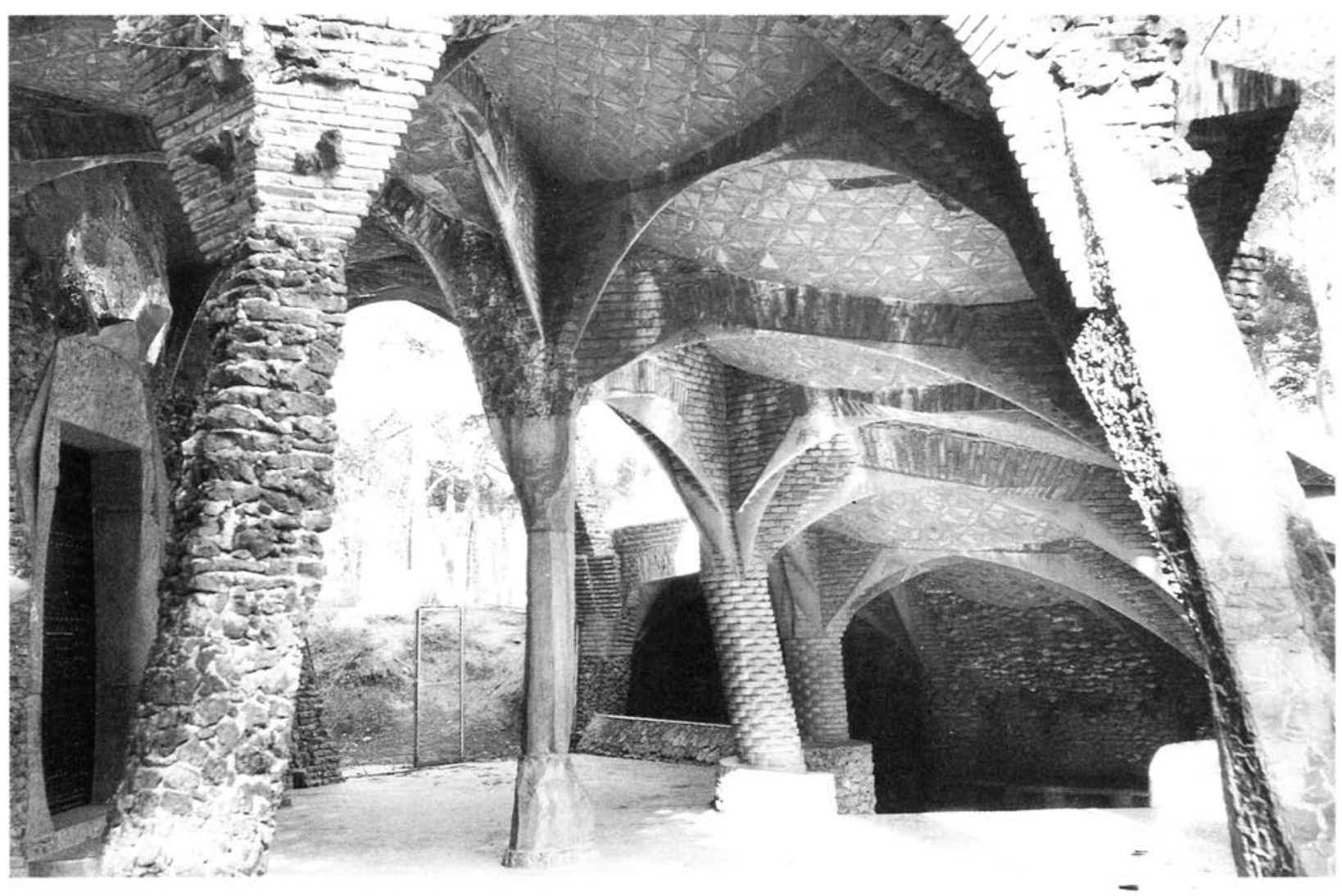

Fig. 10.-Los elementos decorativos añadidos a los puramente estructurales dan un perfil definitivo más similar al de las lineas funiculares. (Foto Arxiu Mas, 1957). 
Sin embargo, el modelo actual no nos permite entender el porqué de ciertas disposiciones constructivas no derivadas directamente de la formas funiculares y que provocan disfunciones en el comportamiento mecánico general, algunas fácilmente detectables. Por ejemplo, costillas con arranques sobre el arco de sardinel con directrices no alineadas.

O los fustes quebrados de los pilares que nacen en el muro que cierra el altar, con inclinación y directriz también notablemente diferentes a las de la maqueta y también de difícil aceptación como soportes de cargas superiores.

Pero frente a estas cuestiones de relativa importancia la más trascendente se nos presenta también como de difícil interpretación: la contradicción consustancial de un edificio que se concibe en equilibrio entre todas sus partes una vez acabado en su totalidad y que queda a medio hacer. Si es estable antes no lo es después o viceversa.

\section{Un equilibrio inesperado}

La contemplación del modelo funicular, además del goce estético y recreación estéreo-imaginativa que de momento ningún ordenador puede proporcionarnos, también permite realizar un ejercicio mental algo perverso pero inofensivo si no traspasa el nivel imaginario.

Si se cortan todos los hilos que parten de los nudos de la cripta inferior dejando a ésta sometida a sus propias cargas, es decir, tal y como está construida en la actualidad, es obvio que la forma que adquiere es notablemente diferente. Las potentes fuerzas que tiran de los hilos superiores de la maqueta son las que les dan sus directrices en composición con las tiranteces de los arcos perimetrales y centrales del techo de la cripta; supuestos suprimidos los hilos de la parte inferior, pasan a dominar las tensiones de los arcos variando la inclinación tanto de las directrices de las paredes perimetrales, como de los pies derechos centrales.

Como la Cripta está construida siguiendo la forma parcial del edificio completo, se ha de suponer que es inestable. Careciendo las paredes de las fachadas de las cargas de la parte superior, los empujes de los arcos perimetrales las desplazan hacia el exterior, al igual que ocurre en cualquier edificio con planta baja abovedada. Por igual razón, al faltar el empuje hacia el interior del arco perimetral, la siguiente crujia y la central quedan desequilibradas, y se arruina todo el conjunto.

Es evidente que la hipótesis es falsa ya que el edificio está en pie.
Un primer tanteo para llegar a una explicación del hecho, puede realizarse según los métodos de la estática gráfica, comprobando si las líneas funiculares producidas por la carga actual de la Cripta no se alejan demasiado del núcleo central de los elementos de soporte.

Para ello es necesario un conocimiento preciso de todos los elementos constructivos que gravitan sobre ellos. Lo cual lleva a interrogarnos sobre un elemento inexistente en el modelo funicular pero de importancia notable: la solera que soportan los arcos de ladrillo y de la cual sólo se percibe su intradós.

La reflexión sobre la función de esta solera como soporte del pavimento por el que discurren los fieles en la iglesia superior, también lleva a preguntar si Gaudi incluyó en sus previsiones la movilidad de éstos y los posibles cambios del trazado de las líneas de presio. nes en función de la variabilidad en la distribución de las cargas.

Hipótesis previas a las prospecciones que se han hecho, aventuraban una solera pesada que disminuyera la influencia de las variaciones de carga. $O$ incluso una cierta heterogeneidad en la distribución de cargas superficiales, que ayudara a paliar los manifiestos desequilibrios existentes, al menos provisionalmente hasta finalizar la iglesia superior.

Realizadas las prospecciones nada de ello se ha encontrado: la constitución del techo en su conjunto es ligera y homogénea en toda su superficie. La solera cuyo intradós es visible desde la Cripta está formada por tres gruesos de rasilla con un espesor total de $6 \mathrm{~cm}$. Sobre ella, un sistema de tabiquillos de la altura de un solo ladrillo de canto soporta una segunda solera de dos gruesos de rasilla, que se supone recibiría el pavimento definitivo. El conjunto total sólo alcanza un peso estimado de $200 \mathrm{~kg} / \mathrm{m}^{2}$.

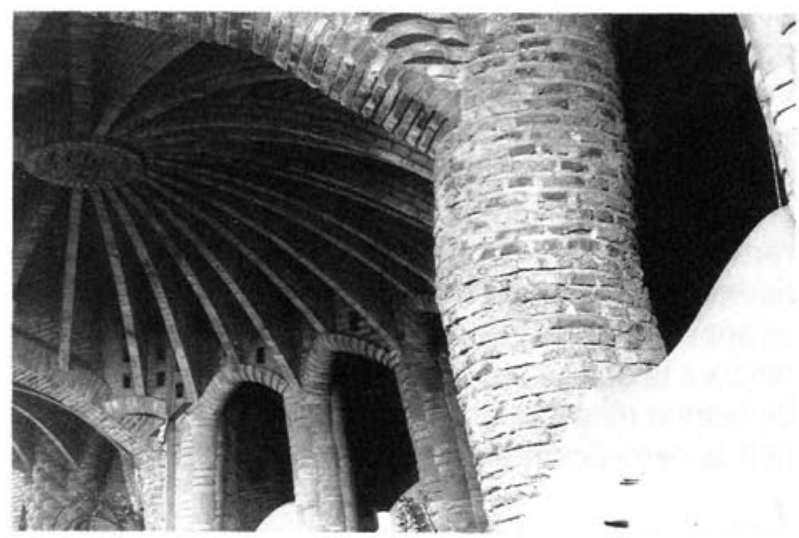

Fig. 11.-El fuste quebrado (1989) 


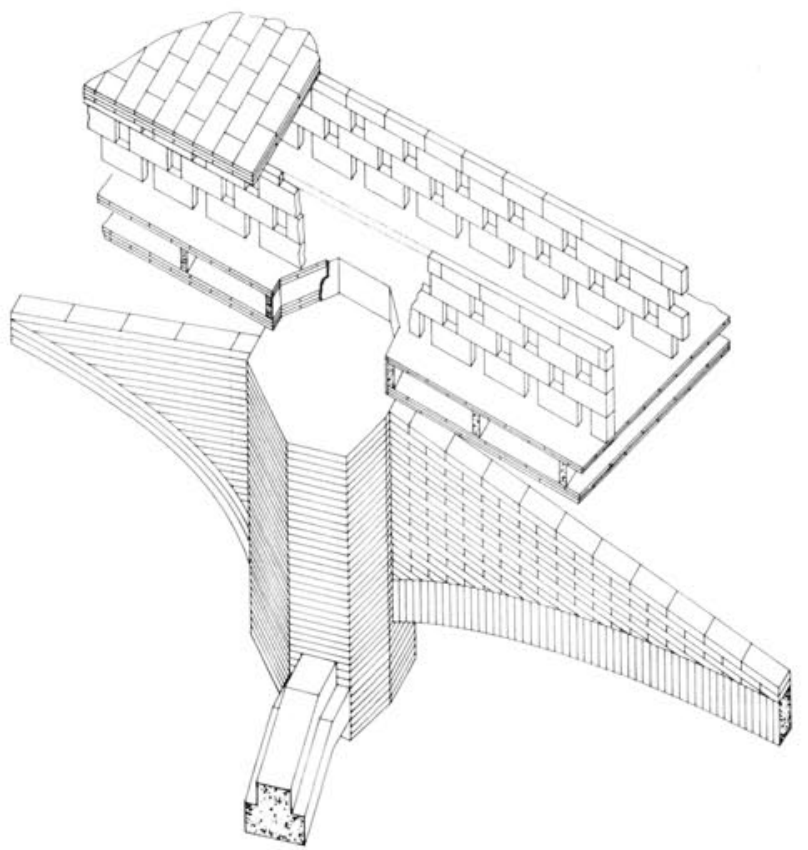

Fig. 12.-Detalle constructivo de la solera superior y de la cubierta a la catalana.
En la actualidad, sobre la solera superior se desarrolla una cubierta plana a la catalana y sobre ésta una de fibrocemento apoyada en un entramado de madera, am. bas no previstas en el proyecto original.

Aplicando las cargas actuantes en una primera com. probación estático-gráfica, se pone de manifiesto, al menos teóricamente, la inestabilidad del conjunto.

A partir de este momento empieza a adquirir carácter de mayor trascendencia un hecho generalmente no advertido pero bien significativo: el intrincado mapa de fisuras que ostenta la solera de rasilla que cubre la na. ve principal de la Cripta. La escasa iluminación, la distancia a la que se encuentra esa especie de lacunario de ladrillo respecto del espectador ordinario, hace difícil la percepción de un hecho tan significativo.

Un análisis detallado mediante observación directa por contacto y levantamiento fotográfico de precisión per-

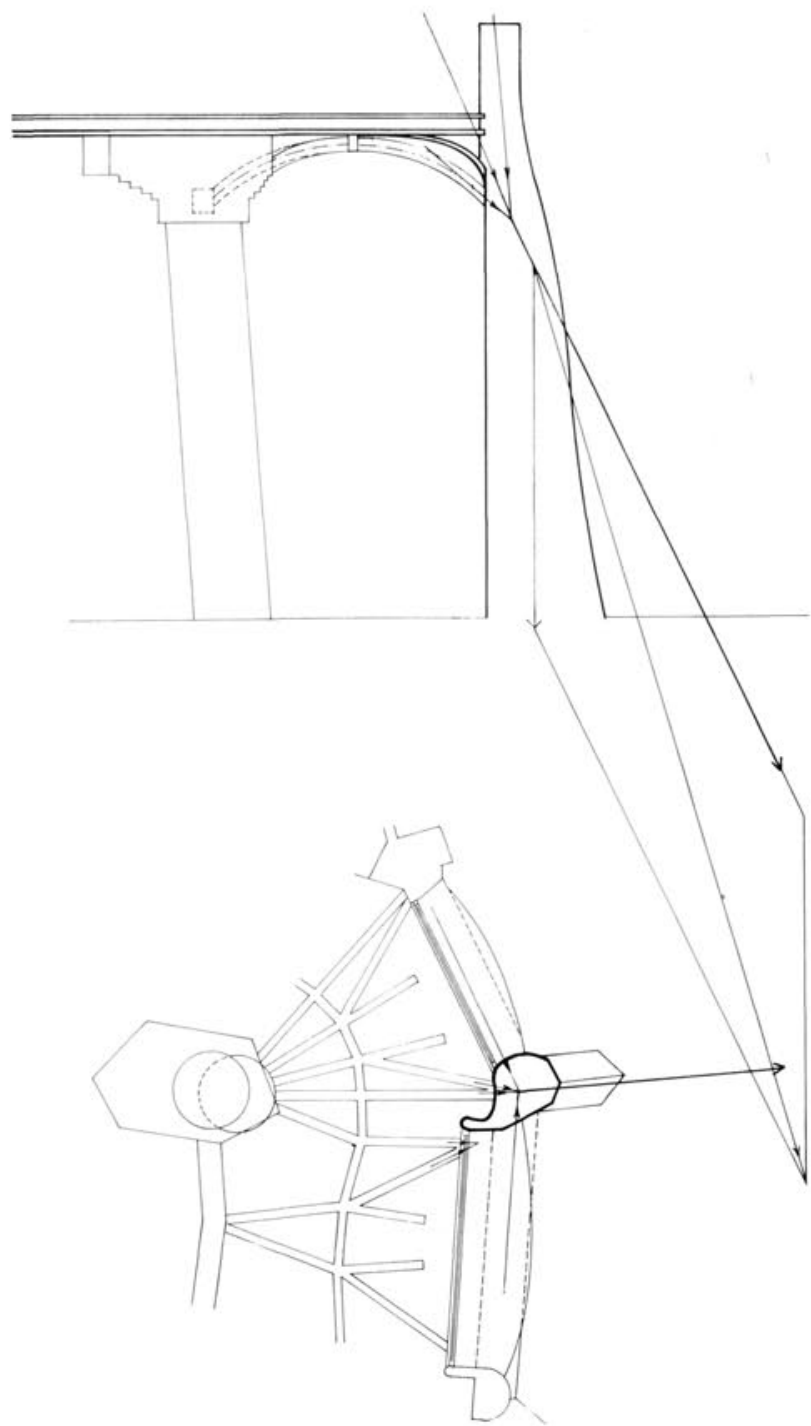

Fig. 13.-Desequilibrio teórico de un elemento de la fachada de la Cripta por la falta del peso del edificio acabado.

mite establecer el mapa de fisuras adjunto. Algunas de ellas son notablemente amplias y han supuesto el desprendimiento de algún fragmento de arcos soportes de la solera. Es, casi con seguridad, un estado de fisuración no progresivo que parece ser consecuencia de un acomodo inicial a un estado de equilibrio diferente del previsto en la maqueta funicular.

Todo ello junto con la continuidad entre la solera y los arcos-costilla, corroborada por deformaciones y fisuras comunes, permite introducir una nueva hipótesis: la solera superior tiene un papel estabilizado de todo el conjunto a modo de placa, aunque no de forma com. pleta sin antes fisurarse.

La ya citada carencia de documentos, impedirá en este caso corroborar si Gaudi consideró esta posibilidad, y que la creencia en ella fue lo que le permitió no adoptar ninguna medida de estabilidad prōvisional hasta la finalización total del edificio. 


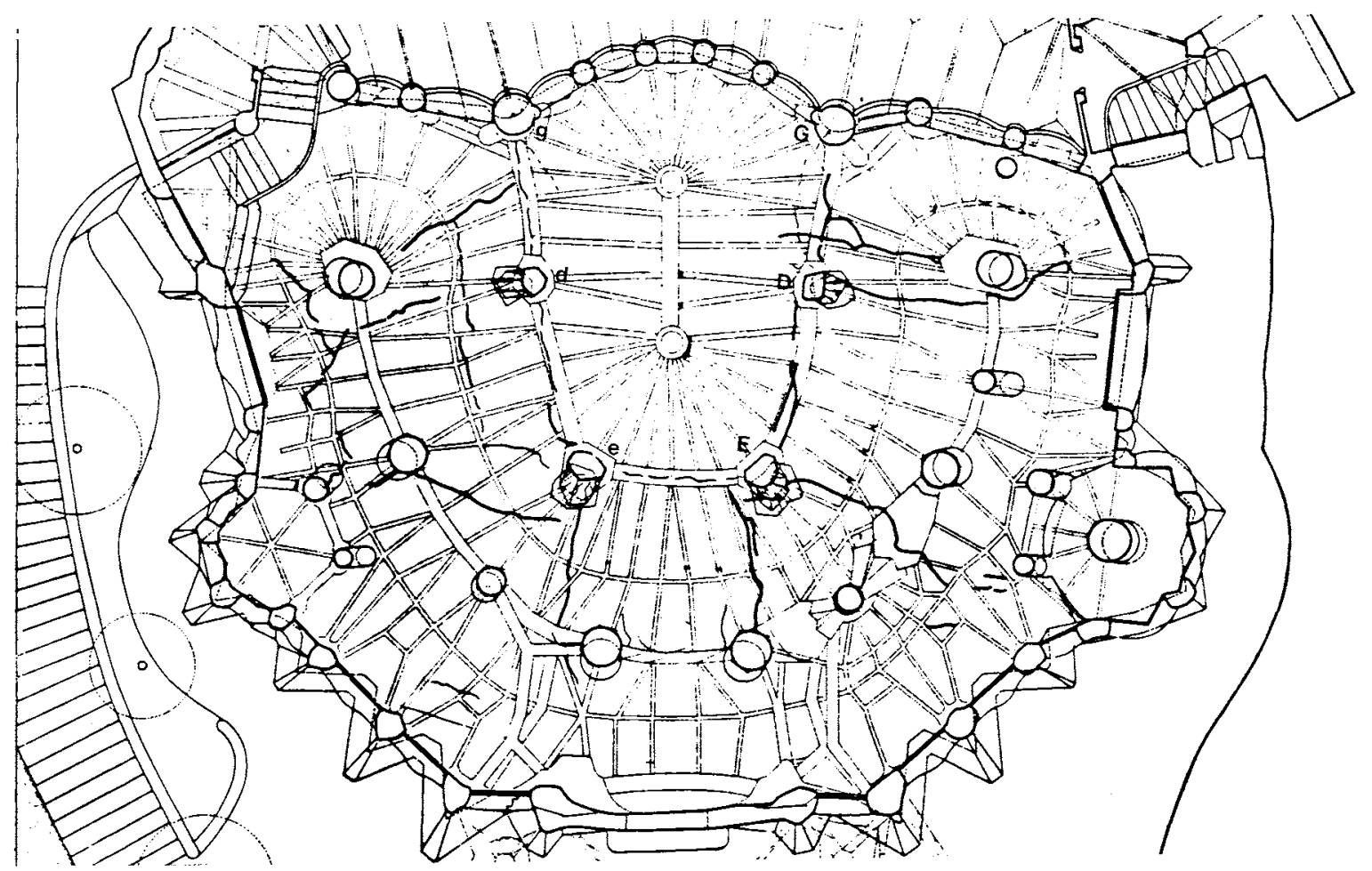

Fig. 14.-Planta cenital de la cripta. Sobre la estructura de arcos principales y secundarios se han grafiado las fisuras que afectan a la solera $y$ los arcos.

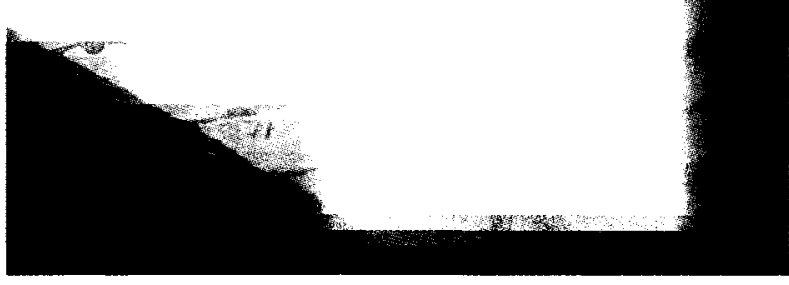

Fig. 15._Fisura de un arco y de la solera (1989).
En cualquier caso, la definitiva comprobación de la hipótesis requiere métodos de análisis más desarrollados que los de la estática gráfica.

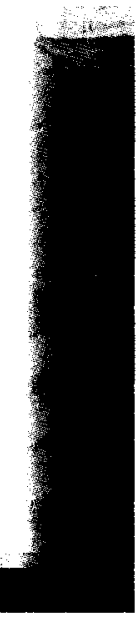

(C) Consejo Superior de Investigaciones Científicas Licencia Creative Commons 3.0 España (by-nc)
Sin embargo, éstos todavia permiten entrever otra de las incógnitas que envuelven a la Cripta, posiblemente la más inquietante. Realmente, ¿hubiera sido estable el edificio una vez concluido siguiendo el proyecto funicular? Varias disposiciones constructivas de la Cripta permiten albergar serias dudas sobre el equilibrio final de todas las fuerzas actuantes. La prioridad del poderoso expresionismo comporta en diversos lugares auténticas transgresiones de las leyes constructivas.

Además de los fustes quebrados ya citados, donde alcanza mayor relevancia tanto la suposición de inestabilidad final del edificio como la prioridad dè la voluntad formal gaudiniana es en la disposición de las columnas de basalto del núcleo de la cripta. 


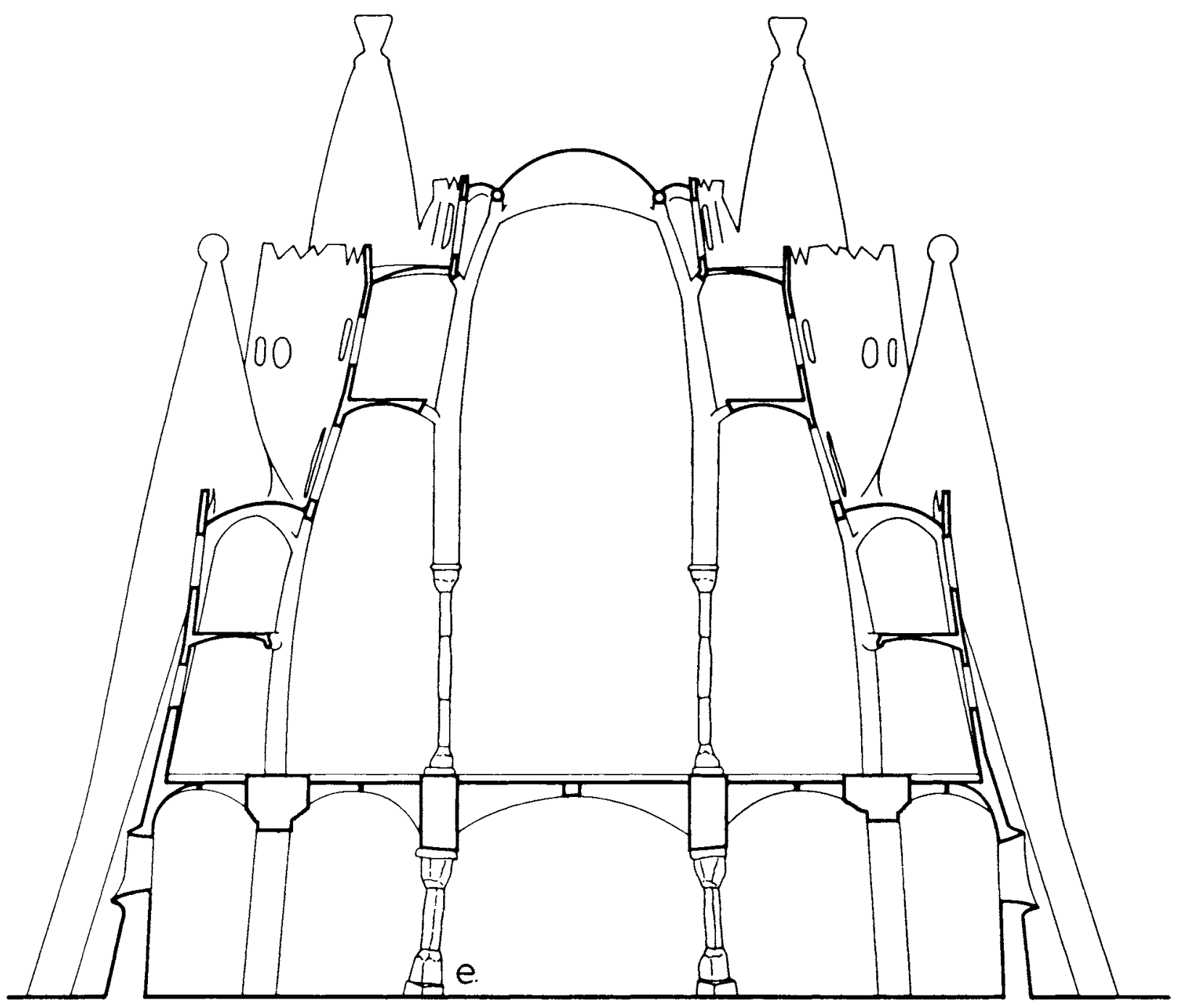

Fig. 16.-Sección del edificio acabado imaginada a partir de las lineas de la maqueta reproducida, de su contraste con dibujos originales de Gaudi y de la Cripta real (realizado a partir de un esquema de Jos Tomlow, op. cit., pág. 210). La línea de los pilares centrales superiores (que no se llegaron a construir) es casi vertical. Los pilares basálticos de la Cripta, que si fueron construidos, son los únicos elementos centrales inclinados.

\section{Un desequilibrio previsible}

Una primera aproximación a cualquier maqueta funicular sencilla y simétrica permite advertir que el arranque de las funículas más cercanas a su centro es casi vertical, y totalmente vertical el de las que se sitúan en el eje de simetría, tal como se advierte en otra de las maquetas gaudinianas (14). Sin embargo los cuatro pilares basálticos centrales $(E, e, D, d)$ siguen un trazado notablemente inclinado.

El no poder observar su disposición en la maqueta auténtica impide conocer el mecanismo original de Gaudi. Sin embargo se puede intuir a partir de la observación de la maqueta holandesa.
Como es de esperar, los hilos de los que cuelgan las bóvedas de la cubierta en el tramo de la iglesia, tienen una inclinación muy próxima a la vertical, lo cual también se puede comprobar en las fotos de la maqueta original o incluso en las fotos repintadas que simulan la visión del espacio de la iglesia. En la realidad cons. truida la verticalidad de los macizos prismáticos de ladrillo que se sitúan sobre los pilares basálticos confirma que es de los arcos hacia abajo cuando se inclinan los pilares (Fig. 16).

En consecuencia, para conseguir la iñclinación de los hilos en el tramo de la cripta correspondiente a los pi- 
lares basálticos reales, queda como único recurso la actuación decidida de los arcos que cuelgan de ellos y que transmiten las cargas de la solera del pavimento de la iglesia y del techo de la cripta.

Pero si los pilares más alejados del altar adquieren su inclinación de una forma casi natural, ya que los dos arcos no son coplanares, no ocurre así con los delanteros. Al estar los dos arcos casi en el mismo plano que el pilar, sólo se consigue inclinar el pilar inclinando notablemente el plano de los arcos anteriores. En definitiva y hablando en términos de la maqueta, los arcos deben tirar mucho de los pilares hacia el centro de la Cripta para conseguir inclinarlos. Pero además de forzar realmente la dirección es preciso que las cargas que penden de ellos sean mayores que las del resto, por lo que la zona de influencia que les afecta, deba cargarse más que el resto. Asi se ha conseguido en el modelo holandés (Fig. 17).

Volviendo al lenguaje de la construcción pétrea se puede enunciar lo anterior diciendo que los arcos, además de estar inclinados hacia el interior del núcleo, deben estar notablemente sobrecargados para con su empuje desviar hacia el eje del pilar basáltico la dirección casi vertical de las potentes cargas provenientes del piso superior.

Parece claro que la intención que mueve a Gaudi está más relacionada con la percepción del ámbito central y con la liberación de espacio alrededor del altar, que con la resolución de un problema mecánico.

Pero esta disposición deducida de la maqueta actual no es la que se puede observar en la Cripta realmente construida. Los arcos siguen sólo con un leve gesto el trazado de aquélla y en consecuencia no aportan el empuje que, conjugado con la carga superior, justifica la inclinación del pilar, que en consecuencia debería ser casi vertical (Fig. 18).

Sin embargo, si se aplica la estática gráfica a esta disposición constructiva real si que aparecen componentes inclinadas, pero por diferentes razones a las de la maqueta. La desigualdad de las costillas que descansan directamente en el pilar, la diferencia de las luces de los arcos y su distinto trazado (más tenso el más cargado, d,e), generan una resultante de unas 20 t con una directriz de inclinación notablemente diferente de la del eje del pilar.

Al igual que con lo apuntado para las fachadas, la estática gráfica (que no hace sino reproducir en cada punto la maqueta funicular) nos anuncia un colapso, y éste no se produce. Parece claro que las resultantes obtenidas gráficamente son falsas.

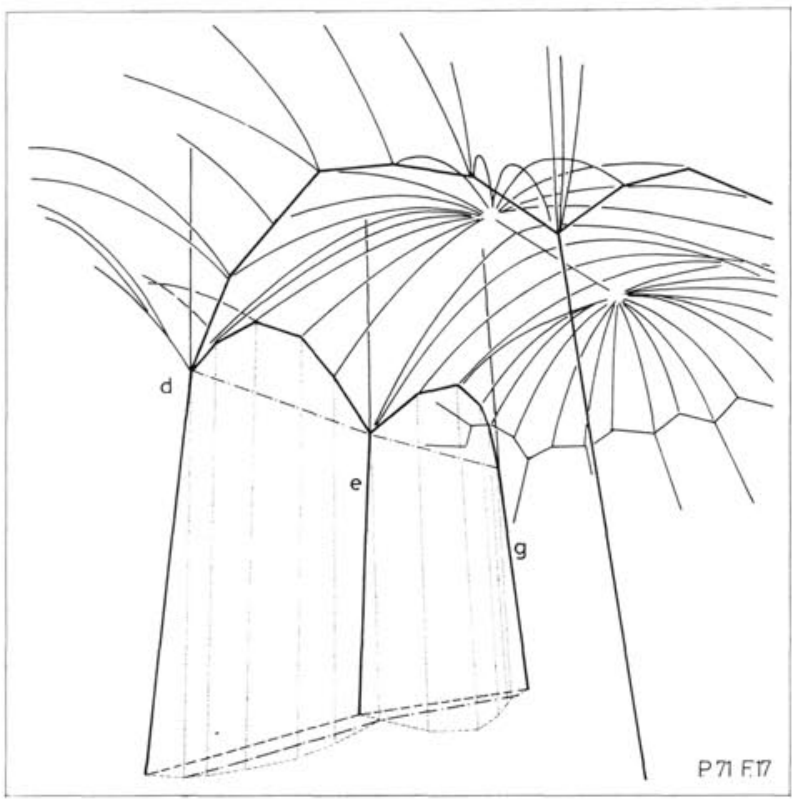

Fig. 17.-El arco g.e de la maqueta se inclina hacia el centro, y por ello consigue inclinar el pilar e. (Dibujo sobre fotografia invertida de la maqueta, Jos Tomlow, op. cit. pág. 182).

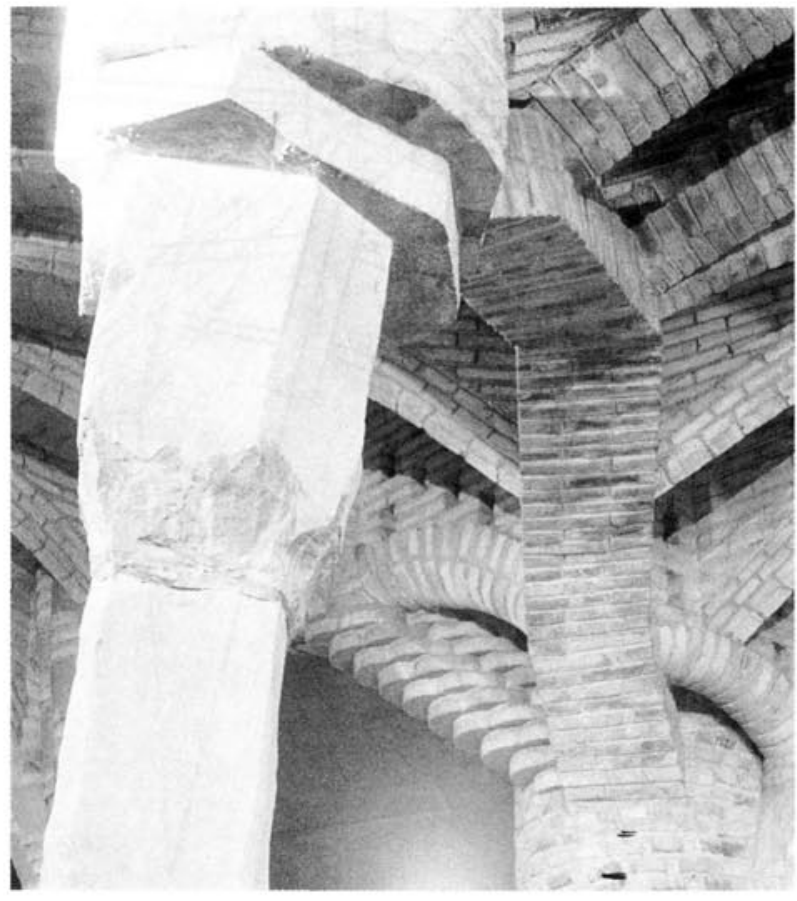

Fig. 18.- Realidad construida del arco g,e (1989).

http://informesdelaconstruccion.revistas.csic.es 


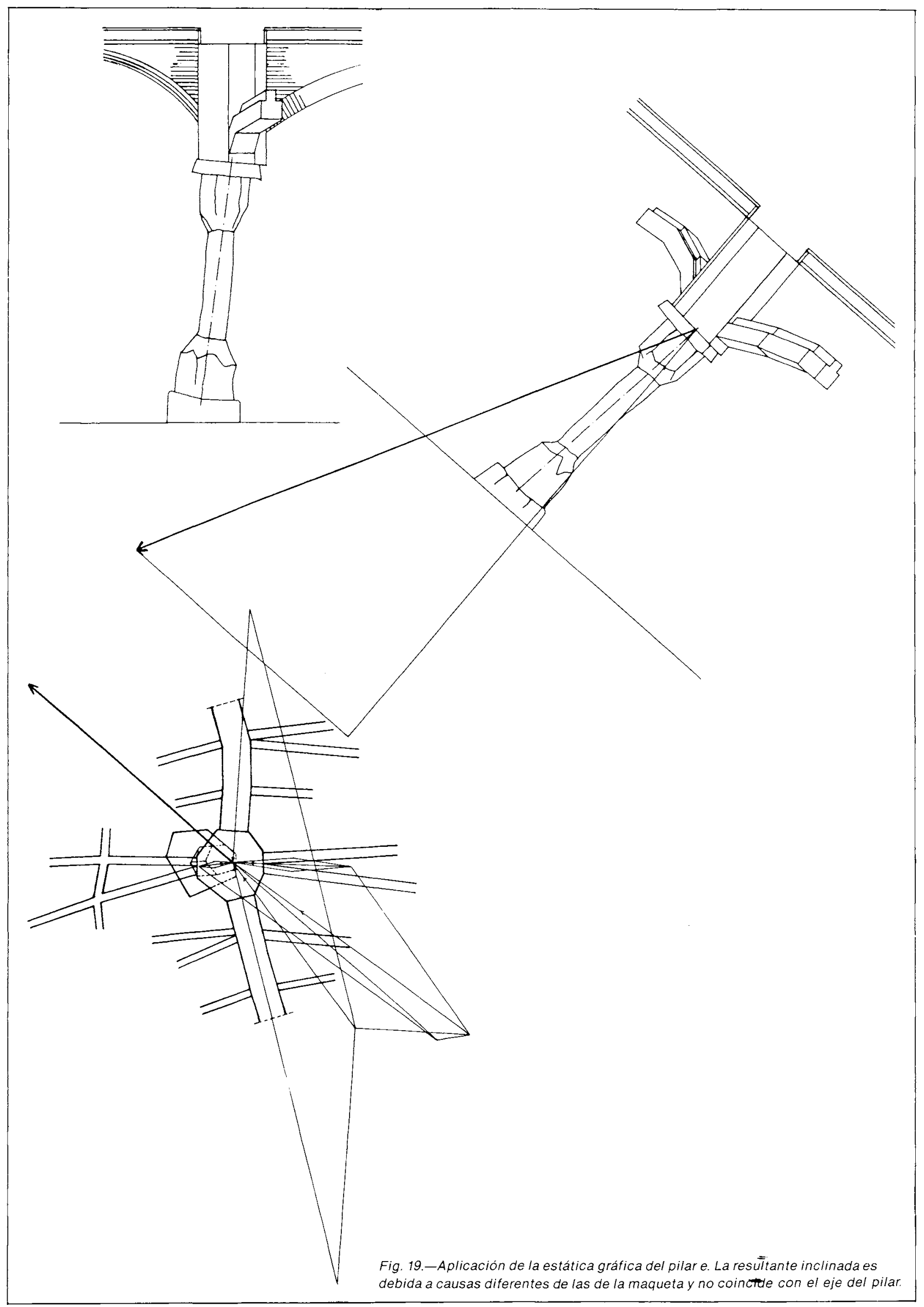




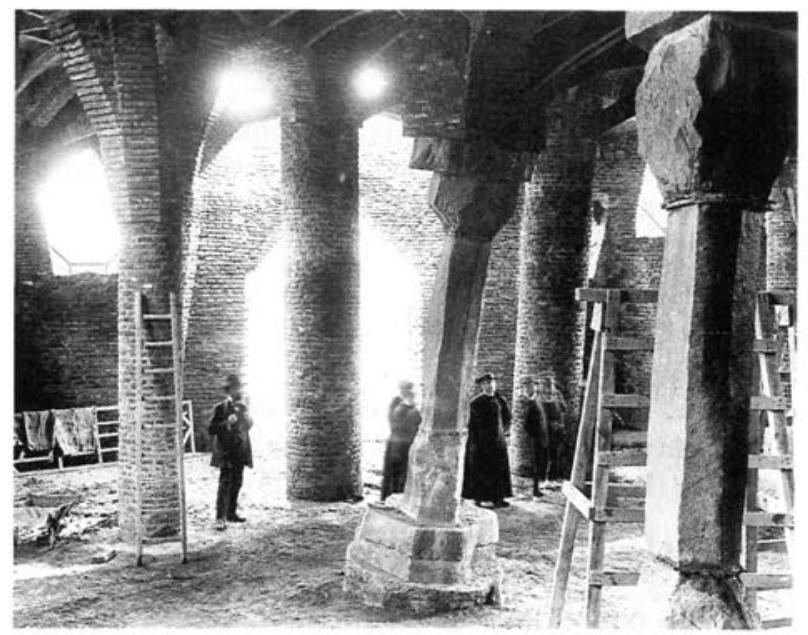

Fig. 20.-La Cripta en construcción. (Foto Antonio Gallardo-Arxiu SPADB, hacia 1912).

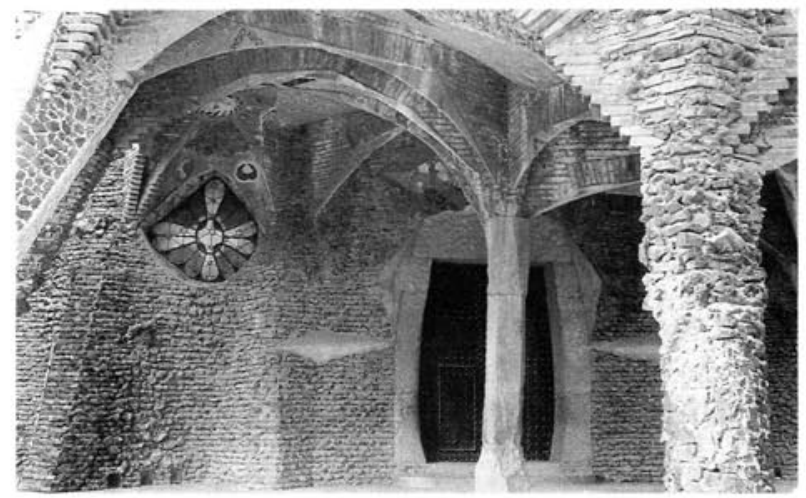

Fig. 21--Pórtico y entrada de la Cripta. (Foto Arxiu Mas, 1957).

Lo único cierto es que existe equilibrio y que las resultantes no pueden pasar alejadas del núcleo central de unos pilares cuya constitución no les permite absorber tracciones.

La explicación puede venir de considerar que los arcos no actúan mecánicamente como tales. La coherencia de una fábrica de ladrillo impecablemente construida en el caso de los arcos principales y la estructura de pared de las costillas, impiden que su deformación sea la de los elementos arcados con doveIas. En consecuencia nos encontramos ante un sistema que se parece más a un conjunto de dinteles y vigas-pared que comportan una mínima generación de empujes.

Si a este sistema añadimos la solera tabicada anteriormente mencionada, que colabora a la estabilidad horizontal a modo de placa, es razonable concluir que estamos ante un edificio cuyo comportamiento mecánico poco o nada tiene que ver con el que implica su modelo funicular.
De aceptar esta hipótesis sobre el sistema estructural, obviamente suficiente para las cargas reducidas actuales, se pone en cuestión nada menos que la estabilidad del edificio totalmente acabado. En efecto, sin ningún empuje que desvíe hacia los núcleos de los pilares basálticos las 40 ó $50 \mathrm{t}$ de directriz casi aplomada provenientes de los pilares superiores, parece lógico albergar serias dudas sobre su equilibrio definitivo.

La trascendencia de esta afirmación respecto del conocimiento del edificio y de la manera de hacer de Gaudi, impone la cautela de mantenerla en la categoría de hipótesis, hasta que se nos presenten nuevos datos. Sin embargo, sin ninguna manifestación del maestro que ilumine la cuestión (15), y sin la documentación que acompañó la construcción será difícil que eso se produzca, a no ser que aparezcan documentos inéditos. Sólo queda como recurso acudir a los nuevos métodos de análisis por elementos finitos que permitirán aceptar o rechazar la hipótesis apuntada u otras que se puedan formular (16).

Pero aunque nos acerquemos a un mayor entendimiénto de la estructura y lleguemos incluso a interpretar satisfactoriamente su comportamiento real, no por ello habremos conseguido desvelar todos los interrogantes que nos han ido apareciendo, cuya resolución Gaudi y la Historia guardaron para sí. En definitiva quedará sin desvelar la clave esencial del edificio, es decir, el misterio de su encarnación.

(1) Roger Scruton. "La estética de la arquitectura". Madrid, Alianza Forma 1985.

(2) Werner Blaser. (Ed.) "Santiago Calatrava". Barcelona, G. Gili 1989 .

(3) Ha sido un tema poco desarrollado por la historia especializada. El único ensayo monográfico es: Juan Bassegoda Nonell. "El Arco de Festón". Mem. de La Real Academia de Ciencias de Barcelona, 1986. El más notable y riguroso estudio de la historia de las estructuras, si bien destaca el sistema gaudiniano, asocia el modelo funicuIar a la Sagrada Familia. Edoardo Benvenuto. "La Scienza della Construzzione e il suo sviluppo storico". Sansoni, Firenze 1981, págs. 342 y 343 . El estudio más reciente del mismo autor relacionado con la cuestión sólo contempla la estabilidad de los puentes. Edoardo Benvenuto, Massimmo Corradi, Federico Foce, "Sintesi storica sulla statica di archi, volte e cupole nel XIX seccolo". In "Palladio" n² 2, diciembre 1988. 
(4) Bergós, Joan. "Conversaciones de Gaudi con Joan Bergós”, en Hogar y Arquitectura, 112, 1974, pág. 54.

(5) El que inició los escritos sobre la Cripta fue: Rubió y Bellver, J. "Dificultats per a arribar a la sintessis arquitectò. nica". Anuario de la Asociación de Arquitectos de Cataluña. 1913. El estudio más completo es: Puig Boada, Isidre. "I'Església de la Colònia Güell”. Barcelona, Lumen 1976. Los más recientes que contienen referencias sobre la Cripta, son: Matsukura, Y. Publicación en japonés sin traducción, que recoge su intento de reproducir el modelo. Tokyo, 1984. Tanaka, Hiroya. Publicación en japonés sin traducción. (Gaudi Architectural works. Drawing of actual measurement, Tokyo, 1987. Bassegoda Nonell, Juan. "El Gran Gaudi". Sabadell. Auxa 1989. Tom. low, Jos. "Das Modell... The Model... El modelo. El mo. delo colgante de Gaudi y su reconstrucción. Nuevos conocimientos para el diseño de la Iglesia de la Colo. nia Güell". Edición trilingüe. Stuttgart. Institut für leichte Flächentragwerke. 1989. Contiene una bibliografia com. pleta.

(6) Jos Tomlow y el Stuttgart Institut für leichte Flächentragwerke, dirigido por Frei Otto.

(7) Tomlow, Jos. Op. cit.

(8) Extracto con el mismo título que el libro, en "Informes de la Construcción". n 404, nov-dic. 1989.

(9) “Presentación". Prólogo al artículo citado en la nota anterior.

(10) El trabajo encargado por el Servei del Patrimoni Arquitectònic de la Diputación de Barcelona, abarca todos los aspectos del edificio, evacuación de aguas, situación de las instalaciones, etc. En el presente artículo sólo se destaca lo que presenta mayor interés general.

(11) En los textos citados de Puig Boada y Tomlow se encuentran todas reseñadas. Las que pueden aportar información sobre la Cripta son las numeradas por Tomlow, OM9 y OM11.

(12) Asi queda afirmado por Bergós en su libro "Gaudi. L'home i l'obra". Barcelona, Ariel 1954 y por César Martinell en "Gaudi i la Sagrada Familia explicada per ell mateix". Barcelona. Aymà 1951.

(13) Véase Tomlow, Jos op. cit., pp., 150, 151, 182 y 183, o bien el extracto publicado en "Informes de la Construcción".

(14) Véase Tomlow, Jos op.cit., o bien el extracto publicado en "Informes de la Construcción". pp. 68 a 70.

(15) La compilación más completa se encuentra en: Puig Boada, Isidre. "El pensament de Gaudi. Compilació de textos i comentaris". Barcelona COAC 1981.

(16) La segunda fase del ya mencionado estudio encargado por la Diputación de Barcelona, incluye la modelización por elementos finitos de la Cripta y una aproximación a la influencia de las cargas superiores en ella. El objetivo del trabajo se limita a llegar a un mayor conocimiento de la estructura de la Cripta que permita prever el efecto de cualquier actuación que se decida sobre ella, por mínima que sea.

\section{Cripta de la Colonia Güell}

c/ Reixac s/n. Colònia Güell (Carretera de Sant Boi de Llobregat a Sant Vicenç dels Horts). Santa Coloma de Cervelló (Baix Llobregat, Barcelona)

Autor: Antoni Gaudi Cornet, arquitecto (1852-1926)

Fecha de construcción: 1898-1914

Propiedad actual: Diputación de Barcelona (compartida). Cesión de uso al Arzobispado de Barcelona Uso actual: Culto católico (Parroquia del Sagrat Cor de la Colònia Güell)

Restauración: Iniciados en 1988 los estudios previos y diversos trabajos de exploración y mantenimiento.

\section{Promotor: Diputación de Barcelona}

\section{Financiación: Diputación de Barcelona}

Técnicos: Antoni González, arquitecto director. Arquitecto colaborador, Pablo Carbó. Arquitectos consultores, Albert Casals y José Luís González.

La iglesia de la Colònia Güell es monumento nacional desde 1969.

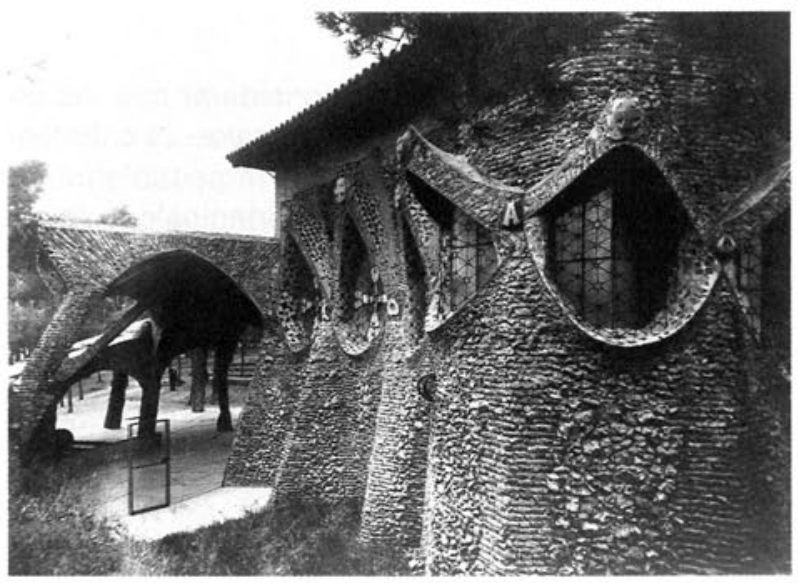

Fig. 22.-Aspecto exterior de la parte del edificio construida. (Foto Zerkowitz) 